\title{
Dental Approach in Individuals with Loeys-Dietz Syndrome: A Mini Review
}

\author{
Tugcenur Uzun ${ }^{1}$ and Busra Bostanci*2 \\ ${ }^{1}$ Department of Oral and Maxillofacial Surgery, Abant Izzet Baysal University, Turkey \\ ${ }^{2}$ Department of Pediatric Dentistry, Abant Izzet Baysal University, Turkey
}

Received: June 3, 2018; Published: June 12, 2018

*Corresponding author: Busra Bostanci, Department of Pediatric Dentistry, Assistant of Professor, Abant Izzet Baysal University, Faculty of Dentistry, Bolu, Turkey

\begin{abstract}
Loeys-Dietz syndrome (LDS) is a connective tissue disease which develops due to the mutations in the genes synthesizing TFG-beta receptors. Hypertelorism, cleft palate with bifid uvula and arterial/aortic aneurysms are the 3 basic elements of the disease forming a triad. Considering oral and maxillofacial findings in individuals with Loeys-Dietz syndrome, the responsibility of dentist is very important both in diagnosis of syndrome and in treatment. In the literature, there has been no publication of a dental approach to LDS and it is expected that this publication may be a guide to dentists for the syndrome.
\end{abstract}

\section{Introduction}

Loeys-Dietz syndrome is a rare disease with autosomal dominant inheritance. The disease results from a heterozygous mutation in the TGFBR1 and TGFBR2 genes affecting the connective tissues [1,2]. It was described by Loeys and Dietz in 2005 for the first time [1]. The classical triad of the syndrome consists of

a. Hypertelorism,

b. Cleft palate or bifid uvula and

c. Arterial/aortic aneurisms and/or arterial tortuosity [35].

The skeletal abnormalities of LDS include pectus deformity, scoliosis, joint hypermobility, cervical spine malformations and/ or instabilities, aracnodactilia, and talipes equinovarus [6,7]. The craniofacial findings of LDS include widely spaced eyes, blue sclerae, bifid uvula/cleft palate, and craniosynostosis [8,9]. Accompanying cutaneous findings may include a translucent skin, a soft and velvety skin, milia, easy bruising, and atrophic scars $[10,11]$. The patients with LDS are susceptible to allergic and inflammatory diseases such as food allergies, eczema, asthma, and chronic sinusitis $[11,12]$. Six different types of LDS has been defined based on the presence of mutations. Type 1 includes TGFBR1 (20-25\%), Type 2 includes TGFBR2 (55-60\%), Type 3 includes SMAD3 (5-10\%), Type 4 includes TGFB2 (5-10\%), Type 5 includes TGFB3 (1-5\%), and Type 6 includes SMAD2 (1-5\%) mutations [7].
The disease displays similarities with other connective tissue disorders, like Marfan and Ehlers Danlos syndrome, because of the presence of arterial and aortic aneurysms/dissections. Loeys-Dietz syndrome is differentiated from Marfan syndrome by hypertelorism, bifid uvula or cleft palate, diffuse aortic and arterial aneurysms and tortuosity $[13,14]$. Furthermore, ectopia lentis, a distinctive finding for the Marfan syndrome, is not seen in Loeys-Dietz syndrome [15]. Due to the aggressive arterial diseases and ruptures, the mean survival in LDS (37 years) is significantly lower compared to Ehlers Danlos (48 years) and Marfan (70 years) syndromes $[4,16,17]$. Compared with Marfan's syndrome, dissections and ruptures occur in younger ages and in smaller diameters in LDS [18]. Craniosynostosis is seen in $50 \%$ of the patients with LDS. Craniosynostosis can be evaluated by a three-dimensional tomography. The sagittal suture is found to be prematurely closed and this premature closing can also be observed with the coronal, metopic and squamous sutures [19].

Respiratory distress and obstructive sleep apnea may occur due to the micrognathia and cleft palate of the disease. Obstructive sleep apnea can also be seen in Marfan syndrome [20]. Betaadrenergic receptor blockers or angiotensin receptor blockers and anticoagulants are used in the treatment of LDS. Angiotensin receptor blocker losartan has been shown to slow down the development process of aneurysms [21]. Patients should be warned that they should avoid challenging exercises and exercises which 
may cause joint injuries. Congenital heart diseases including the bicuspid aortic valve, atrial septal defect or patent ductus arteriosus in LDS patients are more common compared to those seen in the general population [22,23]. In addition, a mitral valve prolapse and/or mitral valve insufficiency is also seen in LDS [23-25]. In these patients, oral hygiene should be kept at the highest levels to prevent bacteremia. It should be remembered that prophylaxis may be required before surgery. In addition, hemorrhages may emerge in patients using anticoagulant medications, therefore, rearrangements of the drug regime might be changed by consulting the patient's physician before the surgery.

In patients with LDS, joint hypermobilities are common, including congenital hip dislocations and recurrent and multiple joint subluxations [19]. However, in some patients, there may be a decrease in the joint mobility as well, especially in the hands and feet. In the literature, there are not any studies available demonstrating the relationship between LDS and TME disorders, however, there are studies reporting that there are increases in the subluxation of TME and increases in the signs and symptoms of temporomandibular disease in Marfan syndrome, which is a similar syndrome $[26,27]$. We are of the opinion that LDS may also be associated with TME diseases. Erkula et al. in their study evaluating the musculoskeletal findings in patients with LDS, reported the rates of the high-arched palate, cleft palate, and dolichocephaly as $76 \%, 36 \%$, and $20 \%$, respectively [28]. Malocclusions may require orthodontic treatment due to the high and narrow structure of the palate.

The orthodontic evaluation must definitely be performed in patients with LDS to identify any requirements for treatment. H. Dietz and B. Loeys observed dental damages due to the hypoplasia of the enamel, requiring extractions of the deciduous teeth [19]. Other abnormal findings like a bifid uvula, uvula with raphe, large or long uvula may be observed in LDS patients, however, there are numerous patients with LDS as well, who do not develop these abnormalities. When a dentist observes any abnormalities of the uvula during the oral examination, she or he must evaluate the patient for LDS. LDS has been reported to be associated with osteoporosis and bone fragility in younger ages $[4,29,30]$. Amor et al. have clarified those findings in LDS patients reporting that the TGF- $\beta$ overexpression in osteoblasts results in a lower bone mass, a thin cortical bone, a high bone turnover, and an increased bone matrix mineralization [3]. These changes in the bone structure must be taken into consideration during the dental implant therapy because there are studies in the literature reporting that the rate of bone turnover or osteoporosis affects the success of the implanting [31-33].

\section{Conclusion}

Although Loeys-Dietz syndrome is quite rare, it should be wellrecognized as a syndrome involving many aspects of dentistry. Patients with LDS require a special procedure for the surgical procedures due to the medications they receive and the risk of infective endocarditis. Dentists are involved in the diagnosis of the disease and in the treatment of craniofacial anomalies of the syndrome. From a dentist's aspect, the most important goal is to keep the oral hygiene at the highest level in patients with LDS.

\section{References}

1. Loeys BL, Chen J, Neptune ER, Judge DP, Podowski M, et al. (2005) A syndrome of altered cardiovascular, craniofacial, neurocognitive and skeletal development caused by mutations in TGFBR1 or TGFBR2. Nat Genet 37(3): 275-281.

2. Singh KK, Rommel K, Mishra A, Karck M, Haverich A, et al. (2006) TGFBR1 and TGFBR2 mutations in patients with features of Marfan syndrome and Loeys-Dietz syndrome. Hum Mutat 27(8): 770-777.

3. Ben Amor IM, Edouard T, Glorieux FH, Chabot G, Tischkowitz M, et al. (2012) Low bone mass and high material bone density in two patients with Loeys-Dietz syndrome caused by transforming growth factor beta receptor 2 mutations. J Bone Miner Res 27(3): p. 713-718.

4. Loeys BL, Schwarze U, Holm T, Callewaert BL, Thomas GH, et al. (2006) Aneurysm syndromes caused by mutations in the TGF-beta receptor. $\mathrm{N}$ Engl J Med 355(8): 788-798.

5. Van Laer LH, Dietz B,Loeys (2014) Loeys-Dietz syndrome. Adv Exp Med Biol 802: 95-105.

6. Kalra VB, JW Gilbert, Malhotra A (2011)Loeys-Dietz syndrome cardiovascular, neuroradiological and musculoskeletal imaging findings. Pediatr Radiol 41(12): 1495-504.

7. MacCarrick G, Black JH, Bowdin, El-Hamamsy, Frischmeyer-Guerrerio, et al. (2014)Loeys-Dietz syndrome a primer for diagnosis and management. Genet Med 16(8): 576-87.

8. Takeda N,Yagi H, Hara H, Fujiwara T, Fujita D, et al. (2016) Pathophysiology and Management of Cardiovascular Manifestations in Marfan and LoeysDietz Syndromes. Int Heart J. 57(3): 271-7.

9. (2007) The Loeys-Dietz syndrome. Archives of Disease in Childhood 92(2): 119.

10. Ting TW, Angeline HweiMeeng Lai, Jonathan Tze Liang Choo, Teng Hong Tan, Lai AH, et al. (2014)Loeys-Dietz syndrome in a Southeast Asian Hospital: a case series. Eur J Pediatr. 173(3): 387-91.

11. Loeys BL,HC Dietz, M.P. Adam, et al.(1993) Loeys-Dietz Syndrome, in GeneReviews((R)), AdamMP Editors. University of Washington, Seattle, USA.University of Washington, Seattle. GeneReviews is a registered trademark of the University of Washington, Seattle. All rights reserved: Seattle (WA).

12. Frischmeyer Guerrerio PA, Anthony L Guerrerio, Gretchen Oswald, Kristin Chichester, Loretha Myers, et al. (2013) TGFbeta receptor mutations impose a strong predisposition for human allergic disease. Sci Transl Med 5(195): 195ra94.

13. Meester JAN, Aline Verstraeten, DorienSchepers, MaaikeAlaerts, Lut Van Laer, et al.(2017) Differences in manifestations of Marfan syndrome, Ehlers-Danlos syndrome, and Loeys-Dietz syndrome. Annals of Cardiothoracic Surgery 6(6): 582-594.

14. Kim ST, Brinjikji W, Lanzino G, Kallmes DF (2016) Neurovascular manifestations of connective-tissue diseases: A review. IntervNeuroradiol 22(6): 624-637.

15. Meester JAN, Verstraeten A, Schepers D, Alaerts M, Van Laer L,et al. (2017) Differences in manifestations of Marfan syndrome, EhlersDanlos syndrome, and Loeys-Dietz syndrome. Ann Cardiothorac Surg 6(6): 582-594.

16. Pepin M, Schwarze U, SupertiFurga A, Byers PH(2000) Clinical and genetic features of Ehlers-Danlos syndrome type IV, the vascular type. N Engl J Med 342(10): 673-680.

17. Silverman DI, Burton KJ, Gray J, Bosner MS, Kouchoukos NT, et al. (1995) Life expectancy in the Marfan syndrome. Am J Cardiol 75(2): 157-160. 
18. Loeys BL, Gerber EE, RiegertJohnson D, Iqbal S, Whiteman P, et al. (2010) Mutations in fibrillin-1 cause congenital scleroderma: stiff skin syndrome. Sci Transl Med 2(23): 23ra20.

19. MacCarrickG,Black JH 3, Bowdin S, El Hamamsy I, Frischmeyer Guerrerio PA, et al. (2014)Loeys-Dietz syndrome: a primer for diagnosis and management. Genetics in Medicine 16(8): 576-587.

20. Takenouchi T,Saito H, Maruoka R, Oishi N, Torii C, et al. (2013) Severe obstructive sleep apnea in Loeys-Dietz syndrome successfully treated using continuous positive airway pressure. Am J Med Genet A 161a(7): 1733-1736.

21. Habashi JP, Judge DP, Holm TM, Cohn RD, Loeys BL, et al. (2006) Losartan, an AT1 antagonist, prevents aortic aneurysm in a mouse model of Marfan syndrome. Science 312(5770): 117-121.

22. Van Hemelrijk C, Renard M, Loeys B (2010) The Loeys-Dietz syndrome: an update for the clinician. CurrOpinCardiol 25(6): 546-551.

23. Van De Laa IM, Denise van der Linde, Edwin HG Oei, Pieter K Bos, Johannes H Bessems, et al. (2012) Phenotypic spectrum of the SMAD3related aneurysms-osteoarthritis syndrome. J Med Genet 49(1): 47-57.

24. Van De Laar IM, Oldenburg RA, Pals G, RoosHesselink JW, De Graaf BM, et al. (2011) Mutations in SMAD3 cause a syndromic form of aortic aneurysms and dissections with early-onset osteoarthritis. Nat Genet 43(2): 121-126.

25. Renard M, Callewaert B, Malfait F, Campens L, Sharif S, et al. (2013) Thoracic aortic-aneurysm and dissection in association with significant mitral valve disease caused by mutations in TGFB2. Int J Cardiol 165(3): 584-587.
26. Bauss O, Sadat Khonsari R, Fenske C, Engelke W, Schwestka Polly R, et al. (2004) Temporomandibular joint dysfunction in Marfan syndrome. Oral Surg Oral Med Oral Pathol Oral RadiolEndod 97(5): 592-598.

27. De Coster PJ, Van den Berghe LI,Martens LC (2005) Generalized joint hypermobility and temporomandibular disorders: inherited connective tissue disease as a model with maximum expression. J Orofac Pain 19(1): 47-57.

28. ErkulaG,Sponseller PD, Paulsen LC, Oswald GL, Loeys BL, et al. (2010) Musculoskeletal findings of Loeys-Dietz syndrome. J Bone Joint Surg Am 92(9): 1876-1883.

29. Kirmani S, Tebben PJ, Lteif AN, Gordon D, Clarke BL, et al. (2010) Germline TGF-beta receptor mutations and skeletal fragility: a report on two patients with Loeys-Dietz syndrome. Am J Med Genet A152a (4): 1016-1019.

30. Tan EW, Offoha RU, Oswald GL, Skolasky RL, Dewan AK et al. (2013) Increased fracture risk and low bone mineral density in patients with loeys-dietzsyndrome. Am J Med Genet A. 161a (8): 1910-1914.

31. Okamura A, Ayukawa Y, Iyama S, Koyano K, et al. (2004) Effect of the difference of bone turnover on peri-titanium implant osteogenesis in ovariectomized rats. J Biomed Mater Res A. 70(3): 497-505.

32. De Medeiros F, Kudo GAH, Leme BG, Saraiva PP, Verri FR, et al. (2018) Dental implants in patients with osteoporosis: a systematic review with meta-analysis. Int J Oral Maxillofac Surg. 47(4): 480-491.

33. Giro G, Chambrone L, Goldstein A, Rodrigues JA, Zenobio E, et al. (2015) Impact of osteoporosis in dental implants: A systematic review. World Journal of Orthopedics. 6(2): 311-315.

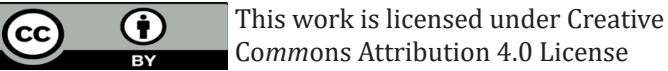

Submission Link: https://biomedres.us/submit-manuscript.php

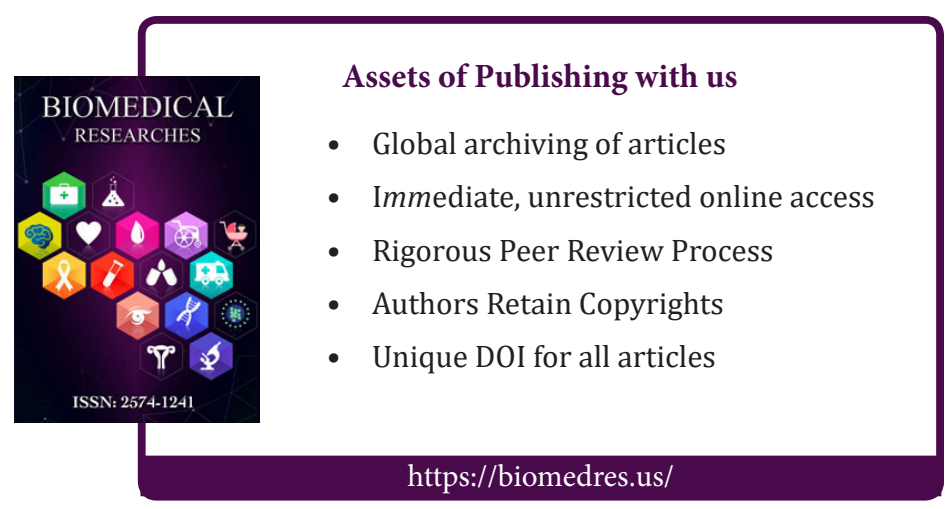

